\title{
IDENTIDADE E INTERLEGALIDADE: DIÁLOGOS POSSÍVEIS ENTRE O LOCAL E O JUDICIÁRIO ${ }^{1}$
}

\section{IDENTITY AND INTERLEGALITY: THE POSSIBLE DIALOGUE BETWEEN LOCAL AND THE JUDICIARY}

\author{
Cíntia Beatriz Müller ${ }^{2}$ \\ Edmundo Fonseca Machado Júnior ${ }^{3}$
}

\begin{abstract}
"We live in a time of porous legality or of legal porosity, multiple networks of legal orders forcing us to constant transitions and trespassing. Our legal life is constituted by an intersection of different legal orders, that is, by interlegality,"

(SANTOS, 1995, p.473).
\end{abstract}

\section{RESUMO}

As comunidades auto-identificadas e reconhecidas como quilombolas no Brasil, via de regra, reivindicam a propriedade de seus territórios ancestrais. Para garantir o direito à propriedade estas comunidades enfrentam um longo processo administrativo que dura anos, podendo levar até mais de uma década. Em não raras vezes há judicialização de questões que atingem diretamente o reconhecimento identitário da comunidade (ou de alguns de seus integrantes), obstam a titulação das terras e que repercutem na demanda por realização de perícia antropológica com a resposta de quesitos. Com base no acompanhamento de um processo judicial sobre território quilombola no qual desenvolvemos atividade pericial propomos analisar as possibilidades de um diálogo "interlegal" no cenário de processos judiciais.

Palavras-chave: Antropologia e Direito. Quilombos Contemporâneos. Interlegalidade.

${ }^{1}$ Parte significativa do texto original foi apresentada na $29^{\text {a }}$ Reunião Brasileira de Antropologia, realizada entre os dias 03 e 06 de agosto de 2014, Natal/RN e agradecemos as sugestões relacionadas à modificação e aperfeiçoamento do mesmo.

${ }^{2}$ Doutora em Antropologia Social. DEA/PPGA, UFBA. E-mail: cintia.beatriz@ufba.br. Salvador, BA, Brasil.

${ }^{3}$ Doutorando em Antropologia. PPGA, UFBA. E-mail: edfmjunior1 @ gmail.com. Salvador, BA, Brasil. 


\begin{abstract}
Communities self-identified and recognized as quilombos in Brazil claim ownership of their ancestral territories. To ensure the right to property, these communities face a long administrative process that lasts years and may take more than a decade. Frequently there are legalization issues that directly affect the identity recognition of the community (or some of its members), prevent the titling of lands, and impact on the demand for conducting anthropological expertise with questions to be answered. Based on the monitoring of one judicial proceeding on a quilombola territory in which we developed expertise activity we propose to examine the possibilities of an "interlegal" dialogue in the setting of legal proceedings.
\end{abstract}

Keywords: Anthropology and Law. Contemporary Quilombos. Interlegality. 


\section{Introdução}

O Brasil possui várias baías e uma das mais representativas é a de Todos os Santos, no estado da Bahia, com uma superfície de mais de 1.000 quilômetros quadrados e uma orla com outros 200 quilômetros (BANDEIRA et al., 2011). A Baía de Todos os Santos (BTS) banha 14 municípios. Três outras baías compõem o sistema da BTS, a Baía do Iguape, Baía de Aratu, que dá acesso ao município de Simões Filho, e a pequena Baía da Ribeira, no município de Salvador. Um rico sistema hídrico deságua na BTS, dentre os rios mais importantes podemos mencionar o rio Paraguaçu, cuja foz forma a Baía do Iguape, rio Subaé, no município de Santo Amaro, a bacia hidrográfica do Rio da Dona, em Jaguaripe, dentre outros. 56 ilhas estão localizadas na BTS sendo a maior delas Itaparica, que se separa do continente por um Canal que leva o mesmo nome. Salvador reúne a franca maioria da população da BTS concentrando mais de $85 \%$ de seus habitantes, de acordo com o Censo do IBGE 2010. (BANDEIRA, 2011; CAROSO et al., 2011)

A região denominada baía do Iguape é composta pelos distritos de Santiago do Iguape e São Francisco do Paraguaçu (BANDEIRA, 2011). As águas desta baía estão englobadas pela Reserva Extrativista ${ }^{4}$ (RESEX) do Iguape, cujo perímetro inclui a área de pesca da região do Iguape, marcadamente de característica artesanal, de tecnologia bastante simples (PROST, 2010, p. 55) e a rica região de mangue. No período da expansão da cultura da cana, nos séculos XVII e XVIII, a região recebeu um grande contingente escravo sendo palco, também, de várias rebeliões. De certa forma, a pobreza contemporânea da região se deve, em parte, a sua herança escravista, sendo uma região com baixo índice de desenvolvimento humano.

Os municípios que margeiam a baía do Iguape são Cachoeira, São Félix e Maragogipe, que juntos reúnem 30 comunidades quilombolas certificadas pela Fundação Cultural Palmares entre os anos de 2004 e 2016, conforme dados apresentados em tabela atualizada até a Portaria

\footnotetext{
4 A RESEX Baía do Iguape possui 8.117,53 hectares de extensão, destes 2.831,24 abrangem manguezais e 5.286,29 águas internas do rio Paraguaçu (PROST, 2010, p.54).
} 
28/2016, publicada no Diário Oficial da União de 07 de março de 2016 e disponível no site da Fundação Cultural Palmares (FCP).

TABELA DE CERTIFICAÇÕES - MUNICÍPIO POR ANO

\begin{tabular}{l|c|c|c|c|c|c|c|c|c}
\hline \multirow{2}{*}{ Município } & \multicolumn{10}{c}{ Certificações / ano } \\
\cline { 2 - 11 } & 2004 & 2005 & 2006 & 2007 & 2009 & 2013 & 2014 & 2015 & Total \\
\hline Cachoeira & 10 & 1 & 2 & 1 & 0 & 1 & 0 & 0 & 15 \\
Maragogipe & 1 & 4 & 5 & 0 & 1 & 0 & 0 & 1 & 12 \\
São Félix & 0 & 0 & 0 & 0 & 0 & 0 & 3 & 0 & 3 \\
Total & 11 & 5 & 7 & 1 & 1 & 1 & 3 & 1 & 30 \\
\hline
\end{tabular}

Fonte:http://www.palmares.gov.br/wpcontent/uploads/2016/04/CERTID\%C3\%95ES-EXPEDIDAS-\%C3\%80SCOMUNIDADES-REMANESCENTES-DE-QUILOMBOS.pdf, 05.maio.2016).

Dentre os 30 quilombos o foco de nossos estudos é o de São Francisco do Paraguaçu, certificado pela Fundação Cultural Palmares (FCP) em julho de 2005. Notório no país por conta de matéria veiculada pela Rede Globo de televisão, em maio de 2007, que colocava em dúvida o autorreconhecimento da coletividade, seu procedimento de titulação continua ativo no Instituto Nacional de Colonização e Reforma Agrária (INCRA). São várias as Ações de Reintegração de Posse movidas por fazendeiros da região e que incidem sobre o TQ (Território Quilombola), a primeira data de 2006, menos de um ano após a emissão da Certidão pela FCP. E é no âmbito destes processos de Reintegração de Posse, movidos na Justiça Federal da Bahia, que Perícias Antropológicas têm sido discutidas e suscitadas. Foi no âmbito do processo 2007.33.00.005218-8, cuja indicação de perito foi solicitada ao Departamento de Antropologia e Etnologia da UFBA, que fui indicada para a realização do Estudo realizado com a assistência de outro historiador e antropólogo, que já havia desenvolvido pesquisa com quilombos na região do Iguape.

Situado em uma área de ocupação escravista antiga que remonta ao século XVII (REIS, 1992) com a fundação de engenhos locais como o Engenho Velho, (MÜLLER e MACHADO JR., 2014), São Francisco do Paraguaçu (SFP) é um povoado bastante antigo. A história do 
povoado se mistura, também, com a do Convento de Santo Antônio, tendo sido construído entre os anos de 1653 e 1686 (MÜLLER e MACHADO JR., 2014). O pedido de instalação do Convento, na localidade de SFP, foi encaminhado pelos próprios moradores locais (FRAGOSO, 2004, p.31), tendo o terreno do Convento sido oferecido pelo Padre Pedro Garcia, no mesmo ano de 1649.

No local onde se situava o Convento, ainda no ano de 1717, "não havia mais do que dois ou três casebres de Pescadores, e o Hospital...". Por volta de 1760, escrevia Jaboatão: "hoje haverá uma dúzia de casas de alguns pobres, que vivem à sombra do Convento...", (Ib., n.489), (FRAGOSO, 2004, p. 25).

Além da mão de obra escrava ter contribuído para a construção do Convento, a presença negra na região, e na localidade, é anterior a isto. O Engenho Velho, ou Fazenda do Engenho Velho, era uma propriedade que dentre seus primeiros donos figuravam membros da família Garcia Araújo. Foi justamente o Padre Pedro Garcia de Araújo que doou à Ordem Franciscana as terras onde, hoje, localiza-se o atual Convento de Santo Antônio do Paraguaçu (1653 - 1686). Ao longo de entrevistas junto aos moradores do quilombo do Paraguaçu são várias as referências de ocupação histórica da localidade que remonta ao século XVII, portanto, e que menciona o deslocamento forçado de pessoas escravizadas para a região do Engenho Velho.

Desde 1835 há registro de "roceiros", "lavradores de mandioca" e pessoas da "lavoura" que cultivavam roças em áreas pertencentes aos senhores de engenho, áreas que não interessavam ao plantio da canade-açúcar. Na região do Iguape, vários destes lavradores podiam ser identificados:

De fato, quase metade dos pequenos agricultores do Iguape vivia nesses terrenos íngremes do canto sudeste da freguesia, em propriedades que João Calmon du Pin e Almeida e Jerônimo Vieira Tosta iriam registrar em 1859 como a Fazenda Santiago e o Engenho da Pena. As duas propriedades, segundo seus donos, continham "terras apropriadas para pequena cultura" - isto é, para mandioca, o feijão e o milho (BARICKMAN, 2003, p. 197). 
Moradores de "casebres de pescadores", em "casas de alguns pobres" e nas "terras apropriadas para pequena cultura", assim como, "roceiros" e "lavradores" eram, em sua maioria, pessoas negras de ascendência africana. O próprio Barickman registra, em 1790, lavradores com o nome de "Rodrigo por sobrenome não perca" e os ex-escravos "Inácia jeje" e "Luís preto foro", nos municípios de Jaguaripe, Nazaré e Maragogipe (2003, p. 249), sendo que este último é município bastante próximo da localidade de SFP. Em conversas com moradores de SFP é recorrente que, em suas memórias, relembrem de negros, moradores antigos, que viviam nas escarpas do tabuleiro do Iguape destacando o plantio, a existência das casas de farinha e o candomblé como emblemas marcadores de identidade.

\section{Perícia antropológica, uma chance de se pensar a interlegalidade?}

O processo de redemocratização influenciou de forma decisiva pleitos políticos e mobilizações sociais no Brasil desde o início dos anos 80 e, especialmente, ditou parâmetros para discussões referentes à Constituição Federal brasileira de 1988, cuja elaboração esteve sob o crivo de diversos grupos sociais. É notória a presença de representantes de sociedades indígenas, advogados e antropólogos, por exemplo, nas discussões da Subcomissão dos Negros, Populações Indígenas, Deficientes Físicos e Minorias, no âmbito da Assembleia constituinte. Da mesma forma, houve pressão por parte de grupos e atores relacionados ao movimento negro brasileiro na consolidação do pleito de reconhecimento da diversidade e garantia de direitos a esta parcela da população. Esta participação pode ser percebida nos extratos da discussão sobre a redação do artigo 68 do Ato das Disposições Constitucionais Transitórias da $\mathrm{CF} / 88$ que estendia o direito de propriedade, originalmente, às "comunidades negras" e que através de manobras políticas, passaram a ser denominadas como "remanescentes das comunidades de quilombos" (SILVA, 1996; MÜLLER, 2011).

Uma das vitórias registradas no texto da Constituição é o caráter

pluriétnico do Estado brasileiro (PEREIRA, 2002), o que amplificou o campo de possibilidades hermenêuticas de juristas e profissionais 
envolvidos com o campo do Direito. Isto obrigou, também, o país, enquanto Estado-Nação, a reconhecer a alteridade circunscrita a suas fronteiras nacionais, expressa através de múltiplas identidades e práticas culturais. Tal alteridade, contudo, não se encontra adstrita ao reconhecimento de diferentes sociedades que compõem o país, mas, com a noção de cultura assegurado no art. 216, este reconhecimento é estendido aos diversos "grupos formadores da sociedade brasileira" uma vez que todos são reconhecidos como componentes do que seria o patrimônio cultural brasileiro. O texto constitucional em várias outras passagens (PEREIRA, 2002) desconstrói a homogeneidade artificial, imposta pela perspectiva da administração pública e de construção de um Estado nacional colonial, e passa a obrigar diferentes órgãos do Estado brasileiro a atuar junto a grupos diferenciados.

$\mathrm{Na}$ tarefa de possibilitar aos órgãos de Estado uma maior aproximação em relação a grupos específicos, o Estado tem se valido da interlocução com tais grupos através de antropólogos. Este movimento de aproximação, entre antropologia e administração pública, pode ser visualizado através de diferentes processos de integração destes profissionais (antropólogos) nos quadros profissionais de órgãos e instituições públicas, como INCRA e Ministério Público Federal (MPF), e do judiciário, Justiça Federal e Polícia Federal. A interlocução com o MPF teve início nos anos 90 e contou com a aproximação do Ministério Público com a Associação Brasileira de Antropologia. Antropólogos integram os quadros do MPF como "Analista do MPU - Atividade: Perícia - Especialidade: Antropologia", que deve ter por formação curso de Ciências Sociais, com ênfase em Antropologia ou Mestrado ou Doutorado em Antropologia (Edital 2013, Concurso Público MPU ${ }^{5}$ ). Diferentemente, a situação junto ao INCRA que possui em seus quadros "Analistas de Desenvolvimento e Reforma Agrária - Antropologia", no qual a exigência é a de nível superior em Ciências Sociais, com habilitação em Antropologia, ou qualquer graduação com Mestrado ou Doutorado em Antropologia (Edital 2010, Concurso Público INCRA ${ }^{6}$ ), o diálogo

\footnotetext{
${ }^{5}$ Edital, acesso http://www.cespe.unb.br/concursoS/MPU_13_2/arquivos/ED_1_2013_MPU_13_2_ ABERTURA.PDF

${ }^{6}$ Edital, acesso http://www.pciconcursos.com.br/concurso/incra-instituto-nacional-de-colonizacao-ereforma-agraria-550-vagas
} 
com a Associação Brasileira de Antropologia (ABA) é bem mais recente. Pesquisas sobre a atuação dos antropólogos junto a tais instituições ainda são escassas.

A aproximação entre direito e antropologia neste contexto não é algo novo, aparentemente ambos os campos disciplinares teriam muito o que dizer um ao outro. A antropologia encontra-se empenhada em apreender o sentido de práticas locais relacionadas a construção social de legalidades, práticas de justiça e administração de conflitos. O movimento epistemológico imposto pela realização de trabalho de campo e a análise antropológica contribuiria para apresentar diferentes alternativas interpretativas acerca dos sentidos de legalidade que tomam como ponto de partida a análise de casos singulares e o "ponto de vista do nativo". É sobre a dimensão simbólica do direito (OLIVEIRA, 2010), ou seja, sobre o processo social através do qual direitos, oriundos do sistema legislativo ou de base comunitária são vividos e adquirem sentido para coletividades, que incide o interesse de grande parte de pesquisadores envolvidos com o campo de pesquisa que relaciona antropologia e direito.

Coletividades específicas, especialmente os povos tradicionais, buscam acionar e reivindicar direitos ante o judiciário ou no âmbito de instituições muito específicas. A Constituição Federal de 1988 foi o grande disparador destes pleitos ao reconhecer e assegurar direitos aos remanescentes de comunidades de quilombos, sociedades indígenas e todos os grupos "formadores da sociedade brasileira" (art.216, CF/1988). Dentre os grupos formadores da sociedade brasileira há que se destacar aqueles que se caracterizam por serem minoritários, ou seja, grupos que se encontram em relação de assimetria política e econômica, em relação à sociedade envolvente. Estes novos sujeitos de direitos, mas antigos agentes de pleitos sociais, é que se tornaram alvos prioritários de políticas públicas e de estudos feitos por antropólogos vinculados às instituições, desde o final do século XX. A contratação de antropólogos por parte do Estado brasileiro para compor seus quadros institucionais seria parte de seu empenho em assegurar o respeito e a concretização de direitos diferenciados às minorias, que definem o caráter pluriétnico do país.

Um outro movimento identificado no início dos anos 2000 tem chamado atenção: a série de demandas promovidas por delegados de 
polícia e juízes federais junto às Universidades a procura de Antropólogos para realizar perícias em áreas quilombolas. Notadamente áreas já possuem estudos antropológicos realizados por profissionais concursados pelo Estado brasileiro, mas cujos estudos ou são postos em cheque ou são ignorados por membros do judiciário. O que então estaria acontecendo? Se os antropólogos são profissionais concursados e legalmente habilitados para a elaboração de relatórios antropológicos, o que está ocorrendo com seus estudos quando chegam ao judiciário?

Esta articulação entre direito e política se expressa nitidamente também nas pesquisas sobre direitos de cidadania, ou sobre processos que envolvem demandas por direitos de todos os tipos, frequentemente associados a movimentos sociais. (OLIVEIRA, 2010, p. 458).

Professores universitários e antropólogos vinculados aos quadros de órgãos estatais, aparentemente, estão envolvidos com práticas de pesquisa que têm por foco as diversas possibilidades de compreensão de casos empíricos relacionados aos povos tradicionais. Em relação aos remanescentes das comunidades de quilombos, antropólogos estão envolvidos na compreensão e identificação de parâmetros que acabam por assegurar direitos socioculturais ao grupo. Dentre as várias coisas em comum, tais estudos trazem em seu bojo o registro de um conjunto de práticas que os grupos implementam com vistas a garantir a posse e o uso de recursos naturais, a permanência em determinado local ancestral (como práticas relacionadas a sucessão e administração de heranças) e a transmissão de seu próprio patrimônio cultural (saberes e práticas tradicionais), de ordem material e imaterial.

Ao realizar pesquisa junto às comunidades quilombolas estamos dando visibilidade a uma das muitas nuances do pluralismo jurídico que compõe, justamente, o caráter pluriétnico de nosso Estado-Nação. O pluralismo jurídico em sua versão clássica (MERRY, 1988) se atinha ao estudo das relações do direito que sancionava relações entre povos nativos e o direito europeu, ou seja, focava esforços de pesquisa na análise do confronto de sistemas jurídicos de povos colonizados, podemos mencionar aqui, principalmente, os estudos africanos, e o impacto da imposição de normas de concepção europeia em suas coloniais. O moderno pluralismo jurídico (MERRY, 1988), contudo, percebe a diversidade normativa não mais no confronto entre ordens de 
distintos estados nacionais e realidades locais exóticas, mas coloca em evidência a diversidade do interior da própria ordem nacional que é expressa através de práticas e sensibilidades de grupos étnicos, minorias políticas e culturais, dentre outros. O interesse neste momento passa a ser o de entender como diferentes práticas e normas se influenciam mutuamente, interconectando-se e produzindo significados recíprocos em suas variadas dinâmicas e escalas e, até mesmo, práticas que são implementadas em uma zona cinzenta onde a lei estatal não é plenamente eficaz.

Os estudos referentes ao pluralismo jurídico clássico contribuíram decisivamente para o aperfeiçoamento dos estudos com povos estabelecidos em estados nacionais originados de processos de conquista e colonização, como é o caso do estado brasileiro. De acordo com Merry (1988), são três as principais contribuições das pesquisas relacionadas ao pluralismo jurídico em sua forma mais clássica: 1. a análise das relações de interação entre ordens normativas conceitual e estruturalmente diferentes; 2. a compreensão de que o que consideramos como direito consuetudinário é algo oriundo de um processo histórico, o que inclui a interação entre diferentes ordens normativas; e, 3. o registro de situações na interação de diferentes ordens normativas produz movimentos de imposição, dinâmicas de resistência e/ou reestruturação de grupos sociais. Desde sua concepção clássica as diferentes ordens jurídicas sempre foram percebidas como possuidoras de fronteiras porosas, contudo, frente ao movimento hegemônico dos Estados nacionais, especialmente de conquista de povos e territórios, a assimetria de poder de grupos e sociedades frente aos Estados impunha aos primeiros uma permeabilidade sistêmica unilateral, ou seja, historicamente eram os direitos "consuetudinários" que eram obrigados a se transformar.

As análises contemporâneas que levam em consideração o pluralismo jurídico percebem que no interior dos Estados nacionais existe uma certa variedade de ordens normativas e colocam sob os holofotes as relações entre o sistema normativo oficial e outros que se encontram socialmente em paralelo a ele. Neste cenário, direito e sociedade não apenas estão interconectados, como constroem interpretações e práticas recíprocas acerca de diferentes significados da legalidade e, nesta linha, a etnografia trata de forma crítica uma certa ideologia que resume o direito à esfera estatal. As comunidades quilombolas detêm 
um rico arcabouço de práticas normativas que foram historicamente construídas e são atualizadas, práticas estas que se adequam às táticas locais de manutenção do acesso aos recursos naturais, transmissão de bens materiais e imateriais e reprodução sociocultural do próprio grupo.

No cenário do novo pluralismo jurídico, de espaços e ordens jurídicas mais fluidas, sistemas jurídicos com fronteiras porosas passam a se (re)configurar. É neste cenário que a noção analítica de interlegalidade pode nos ajudar a compreender a dinâmica de interações e atualizações de esquemas normativos.

A interlegalidade é a dimensão fenomenológica do pluralismo jurídico. Trata-se de um processo altamente dinâmico porque os diferentes espaços jurídicos não são sincrônicos e por isso também as misturas de códigos de escala, de projecção ou de simbolização são sempre desiguais e instáveis. (SANTOS, 1988, p.164).

A pergunta que provocou este artigo é, então, a seguinte: se um dos papéis dos antropólogos é o de produzir textos etnográficos e em nossas interações com grupos minoritários em meio a pleitos judiciais ou relacionados à administração pública estamos produzindo estudos consideráveis, casos exemplares de pluralismos jurídicos, podemos, também, estar falando em interlegalidade?

\section{A perícia antropológica como possível espaço de interlegalidade}

Realizamos uma perícia em 2014 respondendo um total de trinta e quatro quesitos que nos foram encaminhados na seguinte proporção: três quesitos do Juiz, dezesseis quesitos pelos advogados dos Réus e sete, encaminhados pelos advogados do Autor. Outros oito quesitos da FCP nos foram encaminhados mais tarde. As perguntas do Juiz e dos advogados dos Réus levantavam questões sobre qual era a área e como era utilizada; quem são os quilombolas e por quanto tempo a coletividade ocupa a área. Os advogados dos Réus também solicitaram esclarecimentos sobre o "correto conceito de 'remanescente de quilombos' divulgado" pela ABA. A FCP, Ré no processo, lançou questões sobre o pertencimento étnico, relação com a trajetória histórica do grupo; questionou a origem comum do grupo, relacionada 
à ancestralidade negra e escrava e sua relação com o passado da região; relações com a sociedade envolvente; conflitos, laços de parentesco, religiosidade, "vínculos" com a terra e organização política da comunidade. São estes últimos quesitos (MÜLLER, MACHADO JÚNIOR, 2014), encaminhados pela FCP, que apresentamos neste artigo como expoentes da forma como elementos constituintes da identidade quilombola são elencados a partir da demanda institucional e a partir deles buscamos consolidar um espaço discursivo no qual apresentamos elementos de uma juridicidade local.

\section{A. A relação que a Comunidade Quilombola de São Francisco de Paraguaçu mantém com a área hoje identificada como sendo do quilombo está pautada no pertencimento étnico? Mantém vínculo com a trajetória histórica, social, cultural e geográfica do grupo?}

A relação que a comunidade mantém com a área alvo desta perícia, qual seja Sítio Shangrilá, está pautada no pertencimento étnico. A área integra o território quilombola da Comunidade de São Francisco do Paraguaçu, conforme Relatório Técnico de Identificação e Delimitação (RTID), elaborado pelo INCRA (JUSTIÇA FEDERAL 2007, v.3, p. 565). Podemos conceituar as comunidades quilombolas como grupos étnicos que: "[...] existem ou persistem ao longo da história como um 'tipo organizacional, segundo processos de exclusão e inclusão que possibilitam definir os limites entre os considerados de dentro e de fora" (O'DWYER, 2002, p. 14).

A comunidade quilombola de São Francisco do Paraguaçu mantém relações com a área que entrelaçam aspectos históricos, sociais, culturais e geográficos. Por exemplo, podemos citar a forma pela qual o grupo ainda hoje utiliza os caminhos tradicionais que cruzam a área da perícia em direção ao mangue ou em direção as áreas de extrativismo vegetal (que inclui elementos importantes para a manutenção da economia local como cipós, piaçava e o dendê). Estes locais permanecem na memória do grupo a partir do conhecimento tradicional transmitido pelos antigos moradores aos mais novos, muitos deles parentes dos quilombolas que hoje vivem na comunidade. Merece destaque a importância do caminho do "Areal", "Real" ou "Rial" na comunicação da vila de São Francisco do Paraguaçu e terras 
adjacentes com localidades vizinhas, especialmente, a do Boqueirão e de Saubara ${ }^{7}$.

Em termos sociais e culturais destacamos que a área periciada é extremamente importante para a manutenção de parte significativa da identidade religiosa do grupo, pois nela são realizadas oferendas, reconhecidas como ebós, a entidades afro-brasileiras; na área pudemos identificar lugares sagrados como o da "pedra viva", pedra que "cresce sozinha", pois possui "vida própria", local onde também podem ser depositadas oferendas. Atualmente, a área periciada, também, é utilizada pela comunidade são franciscana para o lazer como banhos de rio e de cachoeira incrementando, assim, as opções de espaços de sociabilidade de toda a comunidade.

Em termos históricos a área periciada está relacionada a outros espaços vicinais que compõem a territorialidade quilombola e mantêm a memória histórica da comunidade atualizada a partir da frequência e convivência em seus espaços detentores de marcos simbólicos. É na área periciada que encontramos as ruínas de diversos fornos e casas de farinha de mandioca; os locais de moradia de personagens que compõem fragmentos da história familiar dos quilombolas, antepassados e moradores da área, como Ambrosina, Xandinha e Balu, Mário Burro, Bizu (ou Bizunga), Guilhermina, "Paizinho". Tais personagens também foram referidos como protagonistas na organização e promoção de práticas de cunho religioso como carurus, ofertados a São Cosme e Santa Bárbara, e sambas de roda.

\section{B. O território identificado resguarda aspectos de uma origem comum, compartilhada e pautada na ancestralidade negra e escrava junto à Comunidade Quilombola de São Francisco de Paraguaçu? Qual a relação desta origem comum com o espaço identificado?}

\footnotetext{
${ }^{7}$ Os quilombolas que vivem na localidade da vila de São Francisco do Paraguaçu e adjacências mantêm relações muito próximas com aqueles que vivem ou viveram nas localidades de Boqueirão e Saubara, podemos reconhecer relações de parentesco, interações pautadas pela sociabilidade e processos de migração que marcam a trajetória histórica dos quilombolas são franciscanos.
} 
De acordo com os dados levantados ao longo da perícia, a memória social do grupo remete ao início da ocupação territorial, vinda da população negra africana na condição de escrava e a instalação de um dos primeiros engenhos de açúcar do Recôncavo da Bahia às margens do rio Paraguaçu, o antigo Engenho Velho, ainda no século XVII. Esta memória se entrelaça com a presença dos religiosos franciscanos e da construção do antigo Convento de Santo Antônio do Paraguaçu (1653 - 1686), cuja edificação seria impossível sem a presença da mão de obra escrava africana e indígena. Outro marco da origem da comunidade, de acordo com a memória social dos são franciscanos, é sua relação com o antigo quilombo do Boqueirão, local que teria reunido negros refugiados do antigo Engenho Velho e outros da proximidade.

Ao viver hoje no território delimitado como da comunidade, o que inclui o Sítio Shangrilá, os quilombolas do Paraguaçu compreendem viver em um espaço de ocupação negra tão antiga que remonta aos tempos do Brasil Colônia. As relações históricas na região demonstram a existência de espaços de subsistência mantidos por negros, que cultivavam roças próprias, ainda dentro do regime escravagista. Da mesma forma, no pós-abolição, muitos destes ex-escravos permaneceram nas mesmas terras de seus então "ex-senhores", estabelecendo relações de dependência com tais "patrões". Sem reafirmar um continuísmo mecanicista, podemos inferir que tais relações, embora tenham se transformado ao longo tempo, mantiveram a assimetria como característica do vínculo entre trabalhadores, em sua maioria negros, proprietários e eventuais "herdeiros" de antigas famílias tradicionais da região.

\section{Quais os nexos existentes entre os atuais integrantes da Comunidade e o passado da região?}

Em termos antropológicos, primeiro, precisamos especificar que: 1) a cultura é dinâmica, ela se transforma e se atualiza com o tempo, a partir de relações sociais entre grupos humanos, mediados ou não por fatores tecnológicos, sejam eles meios de transporte ou veículos midiáticos, por exemplo; e, 2) elementos da organização social de um grupo também passam por mudanças através da interação que este 
mesmo grupo estabelece com a sociedade envolvente, suas instituições e com outros grupos que podem ou não compartilhar uma mesma identidade étnica. Contudo, práticas e crenças são mantidas pelos quilombolas do Paraguaçu, pois estas fazem sentido para eles e são vivenciadas dentro de processos históricos, tendo em vista a preservação da identidade étnica do grupo.

Os quilombolas do Paraguaçu praticam uma série de atividades que desenvolvem a partir de saberes e práticas tradicionais que lhes foram transmitidas por seus ancestrais. $\mathrm{O}$ conhecimento sobre a mata, suas plantas e fauna, é disseminado. Práticas de cura, através do uso de ervas com variadas finalidades fitoterápicas, são ainda hoje implementadas por algumas pessoas da comunidade quilombola em seu cotidiano. A extração da piaçava e a coleta do dendê e sua manufatura, foi fruto do aprendizado de trabalhos manuais que revertem, ainda hoje, para a complementação da renda familiar dos quilombolas. Práticas relacionadas a manutenção do solo para o cultivo, assim como o próprio cultivar, foram aprendidas pelos quilombolas na prática tradicional.

O plantio, principalmente da mandioca, é algo histórico nesta região do Recôncavo da Bahia. Os quilombolas conhecem e mantêm a tradição do plantio e a tecnologia de produção da farinha de mandioca na localidade. Uma das técnicas tradicionalmente utilizadas pelo grupo é a retirada do sumo venenoso da "massa" da mandioca, espremida em um "tipiti", uma espécie prensa feita de um trançado de palha, no qual a "massa" é "torcida" para, depois, ser torrada em tachos de ferro (BARICKMAN, 2003, p. $88-102)^{8}$. Outro meio de reprodução do grupo é a manutenção da pesca e de suas tecnologias como a confecção de redes e o conserto de barcos desempenhado por "calafates" que utilizam a raspa do "pau de biriba" como estopa para reparar avarias em suas embarcações. A ciência da utilização das marés e a observação de seus ritmos, o conhecimento sobre espécies de peixes variados, seus ciclos reprodutivos e a adaptação à escassez e desaparecimento de determinadas espécies, são exemplos da dinâmica cultural do grupo em sua interação com o seu meio ambiente natural.

\footnotetext{
${ }^{8}$ A importância da farinha de mandioca é, pois, indiscutível. Presente nas mesas dos ricos, como nas dos pobres, e nas cuias e baldes que os escravos usavam á falta de pratos, constituía a base da dieta comum. Era, portanto, um produto com um mercado local potencialmente grande (ver BARICKMAN, 2003, p. 88 - 102).
} 


\section{Quais as relações que a Comunidade estabelece com o meio externo, o entorno, e como isto reflete em sua configuração sociocultural e política ao longo de sua trajetória?}

De acordo com os dados registrados ao longo da realização da perícia, identificamos relações da comunidade quilombola com "o meio externo, o entorno" em diversos planos de escala. Podemos apontar três escalas de interação por nós estabelecidos para fins analíticos.

Os quilombolas que cultivam no Sítio Shangrilá residem na vila de São Francisco do Paraguaçu, principalmente, na rua das Flores, conhecida tradicionalmente como "Quebra Louça", por conta da precariedade de locomoção que apresentava em dias de chuva. Além disto, os quilombolas do Paraguaçu que desenvolvem atividades agrícolas e de extrativismo na área, destinam ao povoado a maior parte de seus excedentes. Embora a maior parte da produção de azeite de dendê e farinha de mandioca artesanal seja destinada ao consumo familiar e eventuais trocas entre grupos familiares seu excedente, quando existe, é comercializada nos pequenos comércios da vila. Assim, podemos inferir que a produção dos quilombolas, oriunda do Sítio Shangrilá circula através de uma rede de atores envolvidos no processo de produção e comercialização destes produtos no próprio povoado e além.

Ainda em relação aos vínculos da vila de São Francisco do Paraguaçu com o meio externo e seu entorno devemos destacar a estreita relação com comunidades consideradas vizinhas como Saubara, Santiago do Iguape e Maragogipe. Nas diversas falas ouvidas durante a realização da perícia houve menção a estas localidades, especialmente, quando se referiam a espaços de sociabilidade como a frequência em festas religiosas, de tradição católica e afro-brasileira, tradicionais de cada uma das localidades citadas. Tais ocasiões, que expressam a configuração de um circuito historicamente constituído na região do Recôncavo da Bahia, eram, também, momentos estratégicos da dinâmica de um "mercado" matrimonial (BOURDIEU, 2004). Tais encontros contribuíam e reafirmavam a manutenção e extensão das relações de parentesco e compadrio locais, a exemplo dos encontros ocorridos durante os carurus de Dona Bizunga (Bizu), das festas juninas, que se iniciavam com as comemorações a Santo Antônio e finalizavam com aquelas dedicadas a São Pedro. 
Destacamos a importância dos festejos realizados durante a cerimônia de presente às águas do Paraguaçu, dedicada a Oxum e Iemanjá, realizada em parceria com líderes religiosos de terreiros de outras comunidades quilombolas da região do Iguape. Há um circuito de cerimônias que podem ser realizadas no território quilombola, a exemplo do Kaonge, onde se encontra o terreiro "21 Aldeias de Terra e Mar”, cuja liderança espiritual tem importante papel na realização das oferendas. Os festejos se estendem pelos quilombos de Santiago do Iguape (p. ex., terreiro Casa de Xangô) e São Francisco do Paraguaçu (Terreiro Jitundê, atualmente fechado). Os quilombolas são franciscanos do Paraguaçu, ainda hoje, detêm a atividade da pesca como importante fator de reprodução socioeconômica e cultural na vila, onde a cerimônia religiosa contribui para o sucesso, segurança e fartura ao longo do ano de pescarias.

Em um plano de escala macro, podemos elencar relações externas com diferentes locais e instituições. Em relação à igreja Católica, a instalação do Convento se confunde com a origem e fundação da vila de São Francisco do Paraguaçu. Historicamente pessoas de diferentes grupos sociais buscavam, no local, atendimento médico. Por anos o Convento sediou a prisão e o hospital de Cachoeira, instituições externas com as quais os são franciscanos conviveram por longos períodos de sua história. A relação com as cidades de Cachoeira e Salvador, em princípio baseadas em uma lógica comercial, afirmou-se ao longo do tempo como destino que potencializaria oportunidades de melhora nas condições de vida dos moradores que para lá migravam. Ainda hoje, parte da piaçava extraída das árvores existentes no interior da área periciada após processada é repassada a fabricantes de vassouras e posteriormente a revendedores do município de Cachoeira. Narrativas de moradores antigos contam sobre o comércio com Salvador, através dos antigos saveiristas que vendiam a produção local na feira de Água de Meninos, "paralelos" (pedras de meio-fio para calçadas), tijolos e parte excedente da produção agrícola local, podia ser enviada para a comercialização em Salvador.

Atualmente, podemos identificar que várias pessoas de São Francisco do Paraguaçu têm se deslocado até Salvador em busca de assistência médica. Antigamente, após o encerramento das atividades do hospital 
no Convento $\left(1699-1727^{9}\right)$, a busca por assistência médica especializada se dava com o deslocamento até a cidade de Cachoeira para onde foi transferido o hospital. Atualmente, os quilombolas do Paraguaçu deslocam-se em busca de assistência médica para os municípios de Santo Amaro e, principalmente, Maragogipe - com casos de pessoas que morriam em meio a travessia do rio Paraguaçu. Vários idosos e membros mais antigos da comunidade quilombola vêm a falecer em Salvador, tendo em vista que recorrem a esta cidade na busca de tratamento e, vindo a óbito, a família se vê impossibilitada, por dificuldades financeiras, de trazer os corpos para serem enterrados no povoado de São Francisco do Paraguaçu. Em algumas ocasiões a mediação para tais atendimentos médicos era promovida por proprietários de terras da região. De certa forma, podemos afirmar que o acirramento de conflitos locais pela titulação do território quilombola está funcionando como um catalisador de ondas de migração de quilombolas que tem como destino a periferia da cidade de Salvador.

\section{E. Quais os conflitos estão sendo vivenciados pela Comunidade Quilombola de São Francisco e de que modo isto reflete em sua configuração social e territorial?}

A Comunidade Quilombola de São Francisco do Paraguaçu tem vivenciado conflitos de diferentes ordens. De certa forma, o conflito entre os quilombolas e proprietários de terras da região persiste ao longo dos anos. Este conflito parece, o que foi nossa impressão ao longo dos dias que passamos realizando a perícia, ter se atenuado ao longo das interações cotidianas, contudo, a tensão persiste e podemos

9 "Neste hospital não só se curavam os enfermos de fora, mas também alguns Religiosos, especialmente dos outros Conventos, por não haver neste de Paraguaçu, casa particular de Enfermaria, e no hospital se curavam sem dispêndio algum dos Conventos; e nem este de Paraguaçu gastava coisa alguma de botica, e sustento com os seus doentes, porque até o comer lhe vinha feito da cozinha do hospital. A este se foram também curar alguns religiosos de outras famílias, e da mesma sorte sem dispêndio deles. Foi isto nos principias do ano de 1726, e continuando-lhe as moléstias, que havia tempos o apertavam de fraquezas corporais, e outras no seguinte de 1727 aos cinco de Setembro pelas oito horas da noite (Fr. Bernardo da Conceição, Enfermeiro, grifo nosso), completou o curso da vida com aquela boa opinião, que sempre conservou nos claustros, e com repetidas aclamações de virtude em vozes do povo", ver JABOATAN, 1859, p. 548, n.497. 
percebê-la na interação entre quilombolas e pessoas que se identificam como prestadores de serviço a proprietários de terras da região.

Personagens importantes da comunidade quilombola, na busca pelo reconhecimento de sua identidade e conquista de direitos, morreram ao longo destes anos de luta como Dona Maria e Altino. Este último (citado como Réu nos autos), de acordo com a fala de um membro da comunidade quilombola, teria morrido por conta do desgaste físico e emocional desencadeado por este processo. Outro Réu desta mesma ação, Anselmo, encontra-se doente e afastado de algumas atividades por conta dos desgastes pessoais e emocionais sofridos ao longo do processo de reivindicação do título das terras da comunidade quilombola de São Francisco do Paraguaçu.

As intimações judiciais chegam no território - pudemos observar uma intimação que chegara em um dos dias da perícia - constantemente, sendo repassadas aos integrantes da associação quilombola. A judicialização de questões envolvendo as terras e a morosidade do procedimento de titulação conduzido por parte do INCRA, tem extenuado, mas não desanimado, os ativistas, moradores quilombolas, vinculados à associação. Tal pressão contínua acarreta modificação na configuração social do grupo em função da constante necessidade de renovação e de trabalho de suas lideranças para manter vivo o conjunto de reivindicações junto à comunidade.

Em relação à configuração territorial, a comunidade tem produzido e utilizado as terras do Sítio Shangrilá para garantir sua reprodução econômica, social e cultural na vila de São Francisco do Paraguaçu, mantendo assim suas práticas tradicionais de uso da terra. A área do Sítio encontra-se organizada internamente em porções definidas e ocupadas por membros da comunidade quilombola, tais pessoas, em sua maioria, possuem antepassados que guardavam algum tipo de relação com a área do atual Sítio, antiga Fazenda São Francisco.

\section{F. De que forma o território identificado leva em conta a lógica utilizada pela Comunidade Quilombola de São Francisco de Paraguaçu para delimitar as fronteiras internas e externas ao grupo?}


G. No território identificado como sendo do quilombo, como estão sendo considerados os laços de parentesco, vínculos com a terra, religiosidade dentre outros aspectos e manifestações ligadas à reprodução física, social e cultural do grupo?

Optamos em responder os quesitos 6 e 7 em uma mesma questão por entendê-los interligados, uma vez que a lógica utilizada para estabelecer fronteiras internas e externas ao grupo remete aos aspectos ligados às relações de parentesco, às formas tradicionais de apropriação e uso da terra e manifestações socioculturais. Ademais, ressaltamos que a resposta por nós elaborada não diz respeito à totalidade do território identificado pelo INCRA como referente ao da Comunidade Quilombola de São Francisco do Paraguaçu-Boqueirão, mas às relações sociais e vínculos constituídos pelos quilombolas tendo como ponto de partida a área alvo desta perícia, Sítio Shangrilá, que integra parte do território da comunidade quilombola.

As fronteiras, em antropologia, são limites que definem o grupo étnico. Elas podem ser exclusivas, ou seja, que marcam a exclusão de pessoas de um dado grupo; ou inclusivas, quando operam, principalmente, marcadores de identidade e pertencimento étnico. Uma fronteira de caráter social pode vir a ser traduzida em representação geográfica, isto é o que ocorre em situações de delimitação de territórios étnicos e tradicionais.

Em termos de "fronteiras externas ao grupo", pouco temos a acrescentar para além dos elementos apresentados pelo Relatório Antropológico elaborado para o RTID do INCRA que identifica e delimita o território quilombola de São Francisco do ParaguaçuBoqueirão. Em relação às "fronteiras internas", compreendemos que o quesito questiona quais os elementos da organização social do grupo são acionados na construção dos limites internos do território quilombola.

No que tange à organização social do grupo, as relações de parentesco, vínculo com a terra e seus usos e práticas socioculturais se encontram imbricadas. Para exemplificar apresentaremos parte de uma genealogia que reflete o que queremos dizer. 


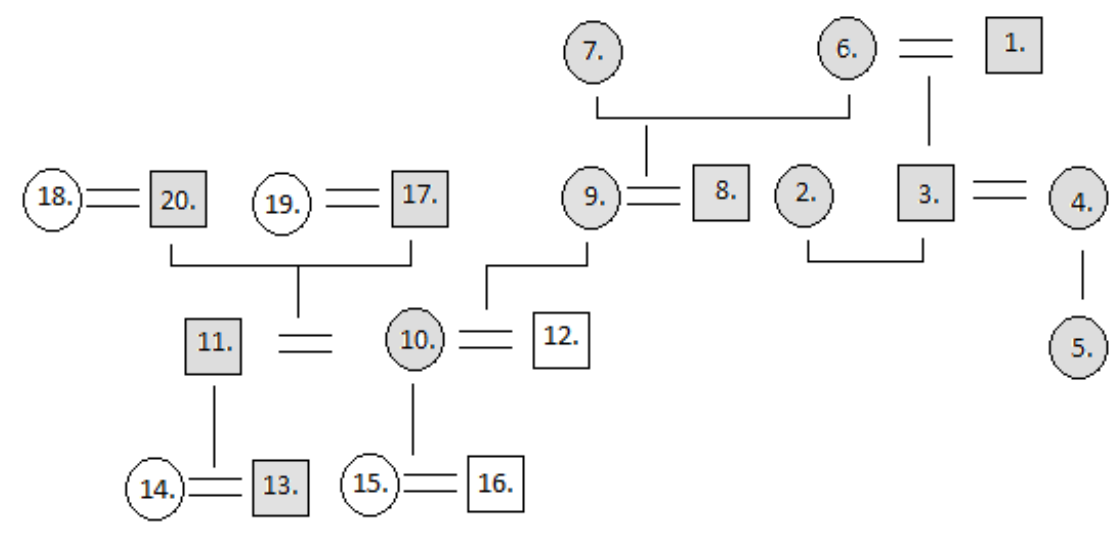

Genealogia exemplificativa das relações de parentesco de pessoas que plantavam e/ou moravam na área do Sítio Shangrilá e adjacências. Todos aqueles marcados com tom de cinza moraram e/ou plantaram e/ou plantam no perímetro do atual Sítio Shangrilá. Restou a dúvida apenas sobre 2. Dona Bizunga (Bizu), que ou morou no perímetro do Shangrilá ou em terras vizinhas, acima da estrada "Areal", "Real" ou "Rial".

1. André dos Santos Reis (38 anos, em 2014). 2. Dona Bizunga (Bizu). 3. Vivaldo (faleceu com aproximadamente 98 anos, em 1998). 4. Nemísia (faleceu com 83 anos, em 2011). 5. Dona Maria. 6. Raimunda Rosendo Silvano (39 anos, em 2014). 7. Valdirene Rosendo Silvano. 8. Antônio. 9. Antônia. 10. Maria Almerinda. 11. Leopoldo. 12. Sérgio. 13. André Reis. 14. Maria "Massuelina" dos Reis. 15. Arcanja Roseno do Carmo. 16 Francisco Roseno do Carmo. 17. Antônio. 18. Zilda. 19. ?. 20. Francinho, Francisco (Pantinho)

Na construção das fronteiras internas do grupo foi possível perceber a relação muito próxima entre os princípios de parentesco, ancestralidade e de residência, ou seja, parentes plantam em terras que seus antepassados plantavam ou próximas a elas. A noção de antepassado pode ser construída tanto a partir do parentesco por descendência, filiação direta, como por aliança, através do casamento, adoção ou compadrio. As situações são perceptíveis no gráfico que trouxemos ao texto.

a) Casal "Antônia" e "Antônio". Antônia (9) foi filha do primeiro casamento de Almerinda (10) (ou Maria Almerinda) com Sérgio (12). Após enviuvar de Sérgio, Almerinda passou a viver em segunda união com Leopoldo (11), cujo pai, André (13), já plantava nas terras do atual Sítio Shangrilá. O casal Antônia (9) e Antônio (8) residiram e 
plantaram nas terras periciadas, próximas às terras de Leopoldo, ou seja, por adoção foi possível ao casal permanecer próximo às terras do velho André.

b) "André Reis", pai de "Leopoldo". André (13) passou as terras ao seu filho Leopoldo (11) e recolheu-se ao Boqueirão, no local chamado "Rio do Pilão" (ou dos "Pilões), manteve, contudo, uma casa na Vila de São Francisco. André Reis ${ }^{10}$ veio a falecer no Boqueirão. O pai passou, a partir do princípio da descendência patrilinear, o direito de plantar nas terras do atual Sítio Shangrilá ao filho Francino ou Francisco (Pantinho) (20). Aqui foram conciliados os princípios da descendência masculina com o da residência como norteadores do princípio da decisão quanto ao local de plantio de filhos.

c) "Raimunda" e "André Reis". O casal planta, hoje, nas terras de Nemísia (4), mãe de André (1), por sua vez, plantou e residiu nas terras onde plantava sua mãe Maria (5). Maria (5) e Nemísia (4) ${ }^{11}$ viveram e plantaram nas terras que seriam do Sítio Shangrilá. Maria faleceu há 39 anos (1975) com 95 anos, ou seja, ela teria nascido em 1880 de acordo com a história familiar do grupo. Raimunda (6), filha de Antônia (9), neta de Almerinda (10), planta, hoje, nas terras que são de André (1) seu marido, demonstrando como o princípio da aliança (o casamento entre descendentes de antigos grupos familiares negros) conciliado com o da ancestralidade da ocupação permite que uma pessoa mantenha, resista e siga plantando nas terras de seus familiares.

Assim, buscamos ilustrar a forma como relações de parentesco, residência e ancestralidade norteiam a organização social do grupo, no que tange a ocupação das terras do Sítio Shangrilá e adjacências (uma vez que a definição deste local é posterior às relações sociais que descrevemos) e a construção de fronteiras internas ao grupo. Trata-se de ocupação tradicional e antiga, que remonta ao século passado, por parte dos quilombolas do Paraguaçu. Podemos citar outros antigos, do

\footnotetext{
${ }^{10}$ Amélia, mãe de Barimbinha, foi quem sentiu falta de André Reis no Boqueirão e perguntou para Rumão, irmão de André que também possuia terras no Boqueirão, sobre seu irmão que, então, estava morto. Esta história nos foi narrada por um senhor de 64 anos que viu apenas uma vez seu avô, André, quando ainda era "meninote".

${ }^{11}$ Destacamos que Nemísia foi casada com Vivaldo, irmão de Bizunga (Bizu). Uma mulher negra de forte representatividade religiosa e social na comunidade são franciscana. Entendemos que Maria e Nemísia devem ter mantido relações, religiosas e sociais, com Bizu, o que as empoderou ao ponto de ter e manter o uso de terras na região.
} 
tempo de Leopoldo, André, Nemísia e Maria, tais como Norato, Totonho do Forte, Mário Burro (sogro de Altino), Balu, "Paizinho" (avô de Da Mata), Babau da Fonte, Maria Antônia, Justiniano dos Santos, Ambrosina, Xandinha, Sapatão, Alipio, Tirita e Bitu que plantavam no perímetro do Sítio Shangrilá e adjacências, de acordo com as informações que nos foram passadas, e que são ancestrais, pelo princípio da descendência ou da aliança, das pessoas que ali plantam atualmente.

Destacamos que André Reis, o velho, e Maria podem ter nascido durante a vigência da "Lei do Ventre Livre" (1871), infelizmente com apenas 5 dias de trabalho de campo não pudemos nos debruçar sobre esta questão específica na busca de registros documentais. Contudo, a exemplo do que já ocorreu em Morro Alto, quilombo na região de Maquiné e Osório, no Rio Grande do Sul (BARCELLOS, 2004), a identificação de pessoas negras nesta região nascidas a este tempo, levou-nos a identificar um espaço de liberdade e autonomia possível de ser exercida pela comunidade negra. Assim tais crianças poderiam ser acolhidas por outras pessoas que lhes garantiriam o sustento e a sobrevivência, como outros grupos de negros livres ou fugidos ainda dentro da ordem escravagista. Avaliamos que isto reforça os argumentos de que a localidade do Boqueirão tenha sido um quilombo histórico da região da Baía de Todos os Santos, com quem já mantinham relações de reciprocidade e solidariedade.

\section{H. Como estão sendo contextualizados aspectos da organização política junto à Comunidade Quilombola de São Francisco de Paraguaçu diante do processo de reconhecimento e regularização fundiária dos territórios quilombolas [sic] Brasil?}

O processo de reconhecimento e regularização fundiária dos territórios quilombolas no Brasil é bastante minucioso e tem seu procedimento administrativo definido através da Portaria 57/2009 do INCRA. Para efetivar o procedimento de titulação e agilizar atos necessários para a concretização do pleito de reconhecimento e titulação das comunidades quilombolas é necessária a constituição de uma associação com personalidade jurídica, que represente formalmente a comunidade. 
A associação está localizada na rua das Flores, antiga "QuebraLouças", e é denominada Associação dos Remanescentes do Quilombo São Francisco do Paraguaçu - Boqueirão. Ao longo do período da realização do trabalho de campo para a perícia, a associação pareceunos bastante ativa e próxima aos moradores da vila de São Francisco do Paraguaçu. Além disso, é através da associação que integrantes da comunidade quilombola, eventuais citados em processos, por exemplo, contatam entidades de advocacia popular para esclarecimentos necessários ao trato de temas jurídicos e administrativos. Integrantes da associação, também, mantêm contato com líderes de outras comunidades quilombolas como a de Salamina e outras, localizadas na região de Maragogipe.

\section{Considerações Finais}

As comunidades quilombolas vivem seu cotidiano e expressam sua identidade buscando permanecer junto ao território que lhes é significativo, que é parte importante do suporte de sua história viva. Para tanto, buscam compor táticas de resistência e de sobrevivência com a confecção de alianças, práticas e reciprocidades que potencializam a manutenção de espaços, materiais e simbólicos, que lhes permitam expressar sua existência no mundo. Tais práticas e saberes configuram um arranjo que podemos, enquanto pesquisadores, apresentar através de espaços porosos do campo jurídico e buscar construir, a partir disto, um contexto favorável à interlegalidade.

A perícia antropológica surge, no âmbito dos processos judiciais, como meio através do qual é possível propor um diálogo entre esquemas jurídicos e legalidades insurgentes. Faz-se necessário, contudo, lutar pela construção deste espaço não apenas com a apresentação de informações, registradas e pensadas a partir do trabalho de campo e de pesquisa minuciosa, mas, muitas vezes, com a relativização e desconstrução dos próprios quesitos que nos são encaminhados. Longe de pensar que estamos em frente a elementos de direito "costumeiro" apenas, mas diante de esquemas que também interpretam legalidades influenciados pelo sistema hegemônico, o processo de interlegalidade pretende amenizar a assimetria de poder entre partes e permitir 
interconexões que garantam a expressão da diferença e reconheça identidades historicamente forjadas.

\section{Referências}

BANDEIRA, F. e BRITO, R.. Comunidades pesqueiras na Baía de Todos os Santos: aspectos históricos e etnoecológicos. In.: CAROSO, C. et al. Baía de Todos os Santos. Aspectos Humanos. Salvador: EDUFBA, 2011. p. 291 - 325.

BANDEIRA, F. et al. Estudo etnoecológico sobre a percepção de riscos ambientais de comunidades ribeirinhas da Baía de Todos os Santos. mimeo, Salvador, 2011.

BARCELlOS, D. M. (et. al.). Comunidade Negra de Morro Alto: Historicidade, Identidade e Territorialidade. Porto Alegre: Editora UFRGS, 2004.

BARICKMAN, B. J. Um contra ponto baiano: açúcar, mandioca e escravidão no Recôncavo 1780-1860. Rio de Janeiro: Civilização Brasileira, 2003.

BOURDIEU, P. El baile de los solteiros. Barcelona: Editorial Anagrama S. A., 2004.

CAROSO, C. et al.(orgs.). Baía de Todos os Santos. Aspectos Humanos. Salvador: EDUFBA, 2011.

FRAGOSO, H. São Francisco do Paraguaçu: uma história sepultada sob ruínas. Salvador: Secretaria da Cultura e Turismo, 2004.

JABOATAN, A. S. M. Novo Orbe Serafico Brasilico ou Chronica dos Frades Menores da Provincia do Brasil. Rio de Janeiro: Typ. Brasiliense de Maximiano Gomes Ribeiro, V.1, 1859.

JUSTIÇA FEDERAL. Processo de Reintegração/Manutenção de Posse 2007.33.00.005218-8. $11^{\text {a }}$ Vara da Justiça Federal. Salvador, Bahia, 2007.

MERRY, S. E. "Legal Pluralism”. Law \& Society Review, Vol. 22, No. 5, 1988. 
MÜLLER, C. B.. Ação Direta de Inconstitucionalidade 3239: uma análise a partir da antropologia do direito. In: Anais da III Reunião Equatoriana de Antropologia/ XII ABANNE, Boa Vista, RR, 2011.

MÜLLER, C. Antropológica B. e MACHADO JÚNIOR, E. F. Perícia Reintegração/Manutenção de Posse 2007.33.00.005218-8. $11^{\mathrm{a}}$ Vara da Justiça Federal. Salvador, Bahia, 2015.

Perícia Antropológica. Processo de Reintegração/Manutenção de Posse 2007.33.00.005218-8. $11^{\text {a }}$ Vara da Justiça Federal. Salvador, Bahia, 2014.

O'DWYER, E. C.. "Introdução". In.: O’DWYER, E. C. (Orgs.). Quilombos. Identidade étnica e territorialidade. Rio de Janeiro: FGV/ABA, 2002.

OLIVEIRA, L. R.. A dimensão simbólica dos direitos e a análise de conflitos. Revista da USP. Dossiê Antropologia do Direito., v. 53, n. 10, 2010.

PEREIRA, D. D.. “O Estado Pluriétnico”. In: LIMA, A. C. S. e BARROSO-HOFFMANN, M. (orgs.). 2002. Além da Tutela: bases para uma nova política indigenista III. Rio de Janeiro: Editora Contra-Capa, pp. $41-47$.

PROST, C. "Resex Marinha versus polo naval na baía do Iguape". Curitiba: UFPR, Novos Cadernos NAEA, v. 13, n. 01, p. 47 - 70, julho de 2010.

REIS, J. J. Recôncavo Rebelde: revoltas escravas nos engenhos baianos. Afro-Ásia. Salvador, n. 15, p. 100 - 126, 1992.

SANTOS, B. S. Uma cartografia simbólica das representações sociais: prolegômenos a uma representação pós-moderna do Direito. Revista Crítica de Ciências Sociais, nº 24, Coimbra: CES, 1988.

. Toward a New Common Sense: Law, Science and Politics in the Paradigmatic Transition. Nova Iorque: Routledge, 1995.

SILVA, Dimas Salustiano. Frechal: Cronologia da vitória de uma comunidade remanescente de quilombo; Constituição e diferença étnica: o problema jurídico das comunidades negras remanescentes de quilombos no Brasil. Boletim Informativo NUER, Florianópolis, v. 1, n. 1,1996 .

Recebido em 25/05/2016

Aprovado em 30/06/2016 